\title{
Cesación tabáquica abrupta vs. gradual: similares resultados de abstinencia
}

\author{
Abrupt vs. gradual smoking cessation: similar abstinence outcomes
}

Lindson-Hawley N, Database of Systematic Reviews 2012, Issue 11. Art. No.: CD008033.

\section{Objetivo}

Determinar si el abandono progresivo del tabaco se asocia con menores tasas de éxito que el cese abrupto en fumadores que quieren dejar de fumar.

\section{Fuentes de datos}

En esta revisión sistemática fueron incluidos diez ensayos clínicos aleatorizados realizados entre 1978 y 2010 en Australia, EEUU, España y Suiza, que habían involucrado 3760 participantes (edad media 42,8 años).

Como resultado principal fue evaluada por intención de tratar la abstinencia a los seis meses de haber dejado de fumar con comprobación bioquímica en siete estudios y, como resultado secundario, los eventos adversos.

\section{Resultados principales}

La tasa global de abandono a los seis meses fue $14,1 \%(11,9$ a 17).

El descenso gradual no fue peor que la interrupción abrupta y el análisis de los subgrupos que usaron o no reemplazo de nicotina y/o métodos de autoayuda y/o apoyo conductual no mostró diferencias.

\section{Conclusión}

Pareciera no haber resultados sustanciales en la abstinencia a los seis meses entre los pacientes que cesan de fumar en forma abrupta y los que lo hacen de manera gradual.

Fuente de financiamiento: no referida.

\section{Comentario}

La Administración de Drogas y Alimentos de EE.UU. (en inglés FDA), la Guía Norteamericana para la Cesación Tabáquica ${ }^{1}$ y la Guía Argentina para la Cesación del Tabaco² recomiendan el cese abrupto como estrategia para ayudar a los fumadores que desean dejar de fumar. Sin embargo, las guías del Reino Unido $^{3}$ y de Australia ${ }^{4}$ aconsejan a los profesionales ofrecer las dos opciones: el cese gradual y el cese abrupto.

Vale destacar que la estrategia de cese gradual es popular entre los fumadores que intentan dejar de fumar y puede ser eficaz, cuando se la implementa en forma estructurada en el marco de una intervención planificada ${ }^{5}$.

Considerando los resultados de esta revisión, éste método alternativo para dejar de fumar podría contribuir a mejorar la adherencia de los pacientes a los diferentes tratamientos con eficacia documentada.

Desde la publicación en 1988 de trabajo de Kottke T y col. ${ }^{6}$, se recomienda planificar dejar de fumar un día acordado (general- mente llamado: día "D") ${ }^{2}$. Se trata de asociar el día de la cesación tabáquica a una fecha importante para el paciente (cumpleaños, aniversario, día del padre, etc.), acompañándolo con estrategias para lidiar con la abstinencia que pueden incluir la sustitución de la nicotina con el objetivo de mejorar su adherencia al tratamiento.

\section{Conclusiones del comentador}

Este trabajo aporta datos para sostener que no hay una clara diferencia de efectividad entre la estrategia de cesación tabáquica abrupta y la de cesación gradual, en términos de abstinencia a los seis meses.

Es importante explicarle al paciente ambas alternativas tratando de consensuar una estrategia de cesación acorde a sus deseos.

Guillermo Espinosa [ Programa de Control de Tabaco del Hospital Italiano de Buenos Aires (GRANTAHI). guillermo.espinosa@ hiba.org.ar]

\footnotetext{
Espinosa G. Cesación tabáquica abrupta vs. gradual: similares resultados de abstinencia. Evid Act Pract Ambul. Ene-Mar 2014;17(1):9. Comentado de: Lindson-Hawley $\mathbf{N}$ y col. Reduction versus abrupt cessation in smokers who want to quit. Cochrane Database of Systematic Reviews 2012, Issue 11. Art. No.: CD008033. DOI: 10.1002/14651858.CD008033.pub3. PMID: 23152252.

\section{Referencias}

1. Fiore M y col. Treating Tobacco Use and Dependence: 2008 Update. U.S. Department of Health and Human Services Public Health Service. Disponible en URL: http://www.ahrq.gov/professionals/clinicians-providers/guidelines-recommendations/tobacco/clinicians/treating_tobacco_use08.pdf (último acceso 07/04/14).

2. Ministerio de Salud. Presidencia de la Nación. Guia Nacional de Tratamiento de la Addicción al Tabaco. 2011. Disponible en URL: http://www.msal.gov.ar/tabaco/images/stories/info-equipos-de-salud/pdf/2013-10_guia-tratamiento-adiccion-tabaco-2011.pdf (último acceso 06/04/14).

3. National Instituto of Clinical Excelence (NICE). Smoking cessation: supporting people to stop smoking. QS43. Disponible en URL: http://publications.nice.org.uk/smoking-cessation-supporting-people-to-stop-smoking-qs43 (último acceso 06/04/14).

4. Autralia Goverment. Department of Health. Smoking cessation guidelines for Australian general practice. Disponible en URL:

http://www.racgp.org.au/download/documents/Guidelines/smoking-cessation.pdf (último acceso 07/04/14).

5. Lindson-Hawley $\mathrm{N}$ y col. Gradual reduction vs abrupt cessation as a smoking cessation strategy in smokers who want to quit. JAMA. 2013 Jul 3;310(1):91-2.

6. Kottke T y col. Attributes of successful smoking cessation interventions in medical practice. A meta-analysis of 39 controlled trials. JAMA 1988;259:2883-9.
} 